\title{
An Examination of the Convergence of Theory in Libraries and Archives ${ }^{1}$
}

\section{By Eric Willey}

ABSTRACT: While the convergence of libraries, archives, and museums (LAMs) has received considerable attention, a literature review indicates that integration has primarily occurred around digitization projects, exhibits, and budgets, while professional identity serves as a barrier to integration of scholarly work. ${ }^{2}$ The present study examines to what extent scholarly theory between archives and libraries has converged by surveying citations from 2008 to 2016 for top-rated library journals in archival journals (and vice versa), examining Library of Congress Subject Headings of cataloged books and dissertations in OCLC WorldCat from 2008 to 2016, and examining papers generated by special projects related to convergence in LAMs. Findings indicate no consistent increase in the number of cross-citations between disciplines in scholarly articles or the number of monographs cataloged with "archives" and "libraries" subject headings in WorldCat that would indicate a convergence of libraries and archives. An examination of papers devoted to the convergence of LAMs shows that while they do not directly address theory and scholarly publishing, they do suggest that distinct professional identities can be considered a barrier to convergence. It is concluded that while LAMs may be converging in some areas, they are not converging in the area of theory, possibly due to a desire to maintain discrete professional identities and low engagement with theory by some archivists.

\section{Introduction}

Librarians, archivists, and museum curators often borrow tools from one another. A finding aid created using Describing Archives: A Content Standard (DACS) rules can be entered into a MARC record in OCLC Connexion software using the Resource Description and Access (RDA) cataloging standard. The Social Networks and Archival Context (SNAC) project uses MARC records, archival finding aids, and authority records from Virtual International Authority File (VIAF), OCLC Research, NACO/ Library of Congress Name Authority File, Union List of Artist Names, and Getty Vocabulary Program to create a research tool that integrates access to resources and biographical historical contexts. ${ }^{3}$ Conceptual models from the museum and library community have been harmonized to create FRBRoo, an object-oriented version of the Functional Requirements for Bibliographic Resources (FRBR) model. ${ }^{4}$ Combined with the desires of patrons to have all information accessible from one search portal, this can be seen as evidence of the convergence of these institutions. However, the presence of split positions and multiple standards implies resistance to that convergence.

The present study examines to what extent theory has converged between the archives and library disciplines by looking for evidence of library journal articles that cite archives journal articles (and vice versa) from 2008 to 2016, counting books and 
dissertations from 2008 to 2016 cataloged in OCLC WorldCat that include the Library of Congress Subject Headings (LCSHs) "libraries" and "archives," and examining five papers that delved into the subject of convergence of Libraries, Archives, and Museums (LAMs). The first two are ways in which theory is disseminated in the profession, while the last offers an overview of convergence. While the term "LAMs" is used throughout the article, particularly when discussing other research that examines all three institutions, the present research is confined to the fields of libraries and archives.

Findings do not support the argument that libraries and archives are converging in regard to theory. No increase has occurred over time in cross-citations or the number of books and dissertations published that have LCSHs for libraries and archives. White papers concerning convergence touch lightly on theory, and, if theory is assumed to be a part of professional identity, it is seen as a barrier to convergence rather than a facilitator. While libraries, archives, and museums may be converging as institutions, people employed in those institutions remain in silos. If convergence is a goal to be furthered, assisting people in opening those silos may be beneficial.

\section{Literature Review}

A literature review provides mixed support for the convergence of archives and libraries. As recently as 2015, the Society of American Archivists published Archives in the Libraries: What Librarians and Archivists Need to Know to Work Together by Jeannette A. Bastian, Megan Sniffin-Marinoff, and Donna Webber. The theme of this work suggests that while archivists and librarians are increasingly working more closely, divisions remain. The authors argued that "the parallel path [of libraries and archives] has not held completely steady, but convergence has not won the day, although there are signs pointing in that direction." ${ }^{5}$ With factors such as services, resources, and combining resources to facilitate the scholarship of patrons driving convergence, and concerns over maintaining discrete professional identities pushing back, the authors envisioned a future in which "archives and libraries are working toward some measure of collaboration and coexistence, if not complete convergence," particularly for large institutions. ${ }^{6}$ While the authors did not specifically address the convergence (or lack of) between archival and library theory, if theory is considered as part of professional identity, it can be considered a factor hampering or limiting convergence in general and would not be expected to occur.

A second work, "From Coexistence to Convergence: Studying Partnerships and Collaboration among Libraries, Archives, and Museums," reports similar findings. Individuals at five separate institutions that were undergoing or had already undergone some form of collaboration or convergence were interviewed, with interviewee Tom Hikerson saying that "the greatest challenges of convergence are connected to professional identity, which in many ways connects to professional expertise." John Wright of Taylore Family Digital Library elaborated on this point, commenting that "converging the thinking is more difficult than adopting similar practices." ${ }^{8}$ The authors go so far as to conclude that "the institutions we studied are attempting to find the right balance 
between respecting professional expertise and merging systems. The success of convergence projects seems to require that one find this balance." ${ }^{9}$ If this is the case, the lack of crossovers in scholarly citations and other works identified by the present research is to be expected.

In her article arguing for integration of archival expertise into the management of born-digital materials, Jackie Dooley stated that "successful digital programs and projects inevitably involve a disparate cast of characters, and administrative boundaries are sometimes permeated." ${ }^{10}$ Dooley further argued that "if the institution does not take advantage of the archivist's array of skills, then others must become well versed in the issues if unpublished digital resources are to be acquired and overseen efficiently, effectively, and responsibly." ${ }^{11}$ In either case, whether archivists work with born-digital materials in libraries, or if librarians acquire archival skills relevant to this area, this represents a convergence of professional duties between archivists and nonarchivists in the area of born-digital materials.

Deanna Marcum provided an exhaustive list documenting "a seeming explosion of conferences, forums, workshops, and other activities devoted to similar ideas” regarding commonalities between and collaborative opportunities for libraries, archives, and museums. ${ }^{12}$ Marcum also commented that considerable progress has been made in overcoming the lack of common standards for describing data that might otherwise impede collaborations. ${ }^{13}$ While some collaborations between LAMs seem to be achievable (such as the creation of exhibitions), others (such as full mergers of collections across libraries, museums, and archives) may prove extremely difficult and even require changes in professional education in the long run. ${ }^{14}$ This suggests that collaboration is easier to achieve in areas where professional practice may be temporarily set aside in favor of providing access (such as the fonds or arrangement of archival materials being set aside for a temporary exhibit, for example), but it does not occur as frequently in other areas such as mergers of collections where standards may conflict. Possible examples of these conflicts include creating cataloging records for finding aids (where inventory lists are often difficult to include) and use of Library of Congress Subject Headings in finding aids in ways that library catalogers might not approve (particularly regarding using subject headings as form or genre terms). In either case, this is an example of patron demand for access driving convergence in ways that might make it conflict with professional practice. It is difficult to say whether this supports or refutes the current thesis further without knowing the content of these conferences, forums, and workshops. If theory is being discussed, this could indicate that theory is converging in different venues than publications are; however, if these events focus solely on practice, that is further evidence that theory itself is not converging.

While Marcum described the considerable progress in creation of common standards, a 2014 study on audiovisual materials in BIBFRAME by Kara Van Malssen notes that "various communities have developed independent content descriptive approaches specific to certain content types and formats. As these approaches are applied to a common data model, search and discovery challenges in library catalogs have become common." 15 
In addition to the integration of various standards in searches, Malssen observed that these independent approaches sometimes provide richer metadata and that,

in addition to the basic user tasks of finding, identifying, selecting, and obtaining content in a catalog, additional, optional questions may also be asked in some cases: What were the circumstances of the work's creation? What additional resources may exist that will assist in contextualizing the content? What are the details of the format(s) on which this content is contained? ${ }^{16}$

The proliferation of formats further confuses the issue of integration, and

there may be a desire among catalogers to align their practice with other content and structure standards available within various AV communities for the purpose of increased interoperability and data exchange, especially when libraries and archives are collecting resources and metadata from broadcast, music publishing, film distribution, or other creative industries that might incorporate very different data models than those found in libraries. ${ }^{17}$

Marcum's findings can be taken in one of two ways: the multiplication of independent standards and alignment of cataloging to those practices can be seen as convergence, or the development of new descriptive approaches can be seen as divergence from traditional practice. It seems likely that, depending on where one looks, both of these cases are true, with catalogers and archivists using what existing standards they can (convergence) while developing independent standards where needed (divergence).

Even as libraries, archives, and museums are converging in certain areas, the nature of Web 2.0 is blurring lines between professionals and the community of users. As Fidelia Ibekwe-SanJuan and Elaine Ménard noted, "A massive adoption of participatory web technologies by the general public has led to a reconfiguration and repositioning of professionals and of the stakeholders in many sectors." ${ }^{18}$ In this instance, Ibekwe-SanJuan and Ménard questioned if the distinctions between LAMs are still valid, or are they "being challenged by digital phenomena and are the boundaries between them becoming porous due to new needs generated by the public social web (for example, 'museolibraries')?" 19 The authors ultimately conclude that

the oft-proclaimed liberating and empowering capacity of Web 2.0 for the general public has not yet taken professional practices in the cultural heritage institutions by storm, whereas it has caused a blurring of frontiers between amateurs and professionals in e-commerce, politics or journalism where UGC, user feedback, and the entry of new players have upset old hierarchies, strongholds, and professional practices. ${ }^{20}$

This reinforces the notion that convergence tends to occur around digital projects, especially when one considers that the general public might well create a digital or online resource with information professionals might consider a mishmash of archival, 
museum, and library materials. If the public is not relying on theory to create their online collections, and those collections are fundamentally the same as those created by archivists and librarians, then digital collections do not represent an area where theory is converging.

In the same issue that Ibekwe-SanJuan and Ménard's article appears, Cheryl Klimaszewski argued that "the lines between the LAMs are blurring as their similarities are emphasized more than their differences. This calls into question not just what LAMs are, it also reveals our expectations about what we believe they should be in the twentyfirst century." ${ }^{21}$ Klimaszewski argued that the "socialization that shapes lumping and splitting emerges from both inside the professions, through practice and preparatory education, as well as through outside forces that include policy makers, government agencies, grant-making institutions, and researchers." 22 While two of the key drivers of collaboration are digitization and finance or budget issues, ${ }^{23}$ it is acknowledged that "LAM re-convergence may not be a new idea, history can neither erase nor negate the century's worth of practices that have developed in the meantime." ${ }^{24}$ In the literature review, Klimaszewski concluded that "a picture is emerging of LAM professionals who are trained in relatively separate traditions within programs at educational institutions that are slow to embrace change." ${ }^{25}$ One manifestation of this training is coursework tailored to archival specialization or a certificate offered within a library program that suggests a lack of convergence between LAMs, with students taking courses and presumably learning theory and practice specific to the subdiscipline of archives.

This may also be a factor inhibiting engagement with scholarly research by archivists. Library schools treating archives as a subdiscipline, rather than a professional discipline in its own right, implies that any archival research or scholarly output is both subordinate to and separate from theory in library and information science. The SAA Guidelines for a Graduate Program in Archival Studies states that "A graduate program in archival studies should provide students with a solid foundation in archival theory, methodology, and practice augmented by instruction in allied fields." ${ }^{26}$ Yet it is worth noting that "graduate programs" in archival studies frequently take the form of specializations, tracks, or certificates in archives that are granted along with an MLIS. Furthermore, it is possible to get a certificate of individual accreditation through the Academy of Certified Archivists without an MLIS by substituting qualifying experience. ${ }^{27}$ While the requirement of core courses in MLIS programs should lead to at least some common ground between libraries and archives and encourage convergence, archivists can and do still come to archives with an MA in history and practical experience, which would discourage convergence.

The lack of dedicated archival graduate programs also discourages doctoral level study, as without a distinct degree program, those wishing to pursue a $\mathrm{PhD}$ in archival studies must instead pursue a PhD in LIS, history, or another field and write their doctoral dissertations on archives. If archivists cannot get a master's or doctorate in their field (or subfield depending on who is being asked), is it any surprise that they are not as engaged with theory? This creates a self-perpetuating cycle where archivists do not get doctoral 
degrees, which leads to a lack of archives faculty, which makes it more difficult and less rewarding for archivists to get doctoral degrees, and so on. Regardless of cause, this is another reason why some archivists do not engage heavily with theory.

The popularity of split positions supports the idea that archives is a professional discipline separate from library and information science. Katherine Ryner stated that in her split position at St. Mary's College of Maryland, "From literally the first day, the library director said you need to split your time half and half." ${ }^{28}$ Ryner's position is not unique, and a 2012 survey by Mary Manning and Judy Silva of college and university archivists found that 150 of 296 (51\%) respondents also had library duties, with many (but not all) dual librarian/archivists being special collections librarians. ${ }^{29}$ Manning and Silva went on to note that their survey revealed a significant number of catalog librarian/archivist positions and that such "dual positions are quite common and not merely in special collections." ${ }^{30}$ The authors sent their survey to archives listservs and targeted individuals who considered themselves archivists with library duties, and they stated that the literature would benefit from "further research targeting librarians with archival duties." ${ }^{31}$ Even with this caveat, the survey found a significant number of people whose positions were specifically described as dual or split between archival and library duties. That people split their duties and time into separate categories and occupy what are specifically described as "split" positions also argues against the idea that LAMs are converging in professional practice. While the impetus for creating a split position may vary (lack of funds or sufficient work for two separate positions seem like probable motives), the very idea of split positions implies separate practices (with different theoretical underpinnings) and workflows performed by the same person.

Manning and Silva's research also raises this question: because dual or split positions exist, do these individuals read and interact with the scholarly literature from archives and libraries, and if so, how? While no research regarding split positions specifically could be located, in a 2009 survey of reading and publishing practices by archivist Cory L. Nimer found that most respondents read The American Archivist, with Archival Issues the second most-read journal. No more than $10 \%$ of respondents read other titles, and, on average, respondents read 1.26 journals regularly, while $25 \%$ answered that they did not read any archival journals. ${ }^{32}$ Nimer went on to report that access may influence this finding, as respondents had the greatest access to The American Archivist and Archival Issues, and an average of 1.6 journals ( $21 \%$ of respondents stated they had access to no archival journals). ${ }^{33}$

Nimer's survey also solicited responses on publishing, finding that $65.8 \%$ of respondents had not published, with publishing rates higher among archival educators (100\%) and those employed by academic institutions (42.9\%). ${ }^{34}$ Upon reviewing the survey results, Nimer concluded that "The data suggest that archivists are reading significantly less journal content than those in the related field of library science and that they are writing at similarly low rates." ${ }^{35}$ Nimer did qualify these findings by noting that some archivists may believe that their practice does not have a theoretical underpinning, and others may identify more closely with other fields such as history. ${ }^{36}$ It should be noted 
that the statement that some members of the archival profession believe their discipline lacks theoretical underpinnings is based on a 1994 debate between Terry Eastwood and John W. Roberts in Archivaria where Roberts asserted that "a considerable portion of it [archival theory] is abysmal claptrap." ${ }^{37}$ It is certainly possible this attitude toward theory changed in the 15-year interval between 1994 and Nimer's article, and further changed in the 23-year interval between 1994 and this article. Still, it seems hard to argue that LAMs are converging in a meaningful way at the theoretical level if archivists are not even reading archival theory, let alone theory in library science, once they are out of graduate school.

In a subsequent study, Kathleen Fear and Paul Conway shed more light on archivists' views of theory and practice. In a survey of Society of American Archivist readers and affiliates regarding The American Archivist, 60.5\% of 494 respondents responded that they felt that the journal was viewed as primarily a scholarly or academic journal by the archival profession in general, and "many of the comments reflect[ed] dissatisfaction with this situation." ${ }^{38}$ Several respondents used free-text fields to elaborate on their dissatisfaction with what they saw as the journal's focus on theory, and the authors quite reasonably concluded that "The variety of commentary and lack of consensus on the proper balance in the journal between theory and practice may be a symptom of the intellectual diversity of the archival profession itself." ${ }^{39}$ A significant segment of professional archivists focusing their reading of scholarly journals and publications on practical advice severely limits opportunities for theories to converge.

A study similar to Nimer's by Laura Manzari asked full-time faculty of American Library Association-accredited LIS programs to rate 89 LIS journals on their importance to research and teaching. ${ }^{40}$ Interestingly, several archival journals appear on this list. Of the 89 journals ranked by mean average (descending, with the highest ranking being 4.04), The American Archivist ranked thirty-third (1.44), Archivaria ranked fifty-ninth (1.01), and Archival Science ranked sixtieth (0.99). ${ }^{41}$ While these are not strong rankings for the archives journals, they do indicate at least some faculty in accredited programs are keeping abreast of archival theory via the published literature.

Finally, in 2016, OCLC sponsored Collective Wisdom: An Exploration of Library, Archives, and Museum Cultures. ${ }^{42}$ This project created an 18-member cohort drawn from libraries, archives, and museums. While the project report notes that the findings were based on the experiences of these 18 individuals and were reflective in nature rather than the result of a literature review or research, it does add that "Arguably, LAM organizations are inherently cross-sector, with shared affinities and needs, yet practitioners tend to retreat to their own affinity groups for answers to professional quandaries." ${ }^{43}$ Again, this suggests a lack of convergence beyond areas where practice is favored more heavily than theory (budget issues, for example), which is in line with previous articles and supported by the present study.

Additional evidence exists that LAMs are converging, but in a sometimes halting and perhaps inconsistent manner. The mere existence of the ALA-SAA-AAM Combined 
Committee on Archives, Libraries and Museums (CALM) suggests that professionals within these institutions are interested in talking to each other, and, if nothing else, the sheer number of acronyms involved demands that they be taken seriously. However, at the May 2017 Society of American Archivists Council meeting, the SAA voted to disband CALM in August 2018. ${ }^{44}$ The council came to this decision after reviewing a report prepared by Council Liaison Rachel Vagts and SAA Chair Lynette Stoudy which said:

For the past few years there has been little or no participation from the American Alliance of Museums (AAM) representative. At the same time, the American Library Association and SAA have had numerous joint initiatives that had appointed task groups completely separate from the membership of CALM. There has been little or no coordination between CALM and those Council-appointed groups. ${ }^{45}$

The August 2018 time was chosen to allow CALM to complete current projects and to prepare a white paper on committee findings. This should not be taken as a rejection of collaboration, but is evidence that CALM might benefit from being restructured and that disbanding and reforming may be the easiest way to accomplish this goal. Council agreed that SAA and ALA (and possibly AAM) leaders "should be engaged in regular communications." ${ }^{36}$ If professional identity is a barrier to convergence (as suggested), a coalition of groups in which people become members based on professional identity may well be a difficult way to achieve convergence.

\section{Journal Citation Methodology}

In selecting library journals to examine, this study relied on the work of others. In 2012, Jungfeng Xia included open access journals in an impact study of library and information science publications. In a break with past studies that utilized impact factors, Xia utilized the h-index to measure rank, stating that the "h-index is an improvement over simple citation measures, emphasizing the total number of citations or publications, and it works properly for comparing publications in the same field." ${ }^{37}$ The five highestranking journals by h-index were Information and Management, MIS Quarterly, Journal of the American Medical Informatics Association, and Journal of the American Society for Information Science and Technology, with Journal of Computer-Mediated Communication and Journal of Management Information Systems tied for the fifth rank with both having an h-index of $44 .{ }^{48}$

In a follow-up study, Judith M. Nixon devised a methodology including "expert opinion surveys, acceptance and circulation rates, impact factors, h-indexes, and journals with local faculty articles" as factors to "create a tiered list of journals tailored to the institution." ${ }^{49}$ After applying this methodology to the 72 refereed titles in the study, Nixon found that "six journals received six or seven tallies each, identifying them as the top six journals: College and Research Libraries; Journal of the Medical Library Association, Library Collections, Acquisitions, and Technical Services; Library Journal; Library Resources and Technical Services; and Reference and User Services Quarterly." 
Five of the top six library journals identified by Judith M. Nixon were checked for archival journal citations. ${ }^{51}$ The study omitted Library Journal (the sixth journal in Nixon's list) because it acts more as a trade journal and does not publish scholarly articles. Archival journals checked for library journal citations included the five journals identified by Nimer as most frequently read, as well as Journal of the Society of Archivists (published as Archives and Records from 2012 forward) and RBM: A Journal of Rare Books, Manuscripts, and Cultural Heritage. ${ }^{52}$ The archival journals were added because there were significantly more articles in the library journal sample than in the archives journal sample, although this still did not create parity in numbers. The additional journals chosen were selected from a short list of archival journals to which the author had access and that covered the date span in question.

Each journal's title was individually searched for electronically, including spelling variations (such as substituting "and" for " $\&$ " and vice versa), abbreviated, and altered journal titles. Search results were then examined individually to ensure that they were actual citations and not false positives (many articles employed the term "provenance" for example, without actually citing the journal Provenance). Scholarly peer-reviewed articles were checked, although editorials, reviews of single monographs, messages from prominent figures, obituaries, and similar articles were not. Multiple citations of different articles in the same article were counted, although multiple citations of the same article in a single article were not (i.e., if "Libraries" by Jane Jones and "Digitization" by Sally Smith appeared in the same article, it counted as two citations; however, if an article cited "Libraries" by Jane Jones five times it only counted as a single citation). This survey intended to measure the breadth of theory integration, therefore one article cited numerous times might convey the impression that a wider range of articles had been included than was necessarily the case.

\section{Journal Citation Limitations}

An obvious possible limitation to the current study is the low amount of engagement with scholarly literature by archivists found in previous studies. If that trend has continued and archivists do not engage with theory or engage with it in avenues other than the scholarly literature, evidence of convergence would not occur there. If this primarily occurs in workshops and conferences, an examination of conference programs and proceedings and workshop topics would be beneficial and possibly refute the current study. Additionally, the five library journals selected may not necessarily focus on publishing in the areas where LAMs are converging. Counting cross-citations for a different selection of library journals may yield different results. The literature review suggests that journals focused on digitization, budgeting, and exhibits may show higher rates of cross-citation than the sample used in this study, although that would leave significant areas of theory outside those subjects unexamined. Further review of additional archives journals may also be beneficial, although such journals are limited in number. Finally, the present work makes no attempt to determine if articles deal with theoretical or practical topics. If these articles were separated by some means and examined discretely, articles that deal with theory might increase over time. 


\section{Journal Citation Results}

In total, 770 archival journal articles and 1,055 library journal articles were examined. Aggregate findings for the citation examination are presented below. Each chart shows the number of times that journals in that discipline cited one of the journals in the other discipline for each year. For example, the articles in the 2014 archives journals examined contain 8 citations for articles in College and Research Libraries (see table 1). Furthermore, Archivaria was not cited in the library journals examined for the year 2014 (see table 3).

Table 1: Number of Library Journal Citations Found in Archival Journals, 2008-2016

\begin{tabular}{|r|r|r|r|r|r|r|r|r|r|r|}
\hline & 2008 & $\mathbf{2 0 0 9}$ & $\mathbf{2 0 1 0}$ & $\mathbf{2 0 1 1}$ & $\mathbf{2 0 1 2}$ & $\mathbf{2 0 1 3}$ & $\mathbf{2 0 1 4}$ & $\mathbf{2 0 1 5}$ & $\mathbf{2 0 1 6}$ & Total \\
\hline $\begin{array}{r}\text { College \& } \\
\text { Research Libraries }\end{array}$ & 3 & 2 & 6 & 2 & 3 & 3 & 8 & 16 & 1 & 44 \\
\hline $\begin{array}{r}\text { Journal of the } \\
\text { Medical Library } \\
\text { Association }\end{array}$ & 0 & 0 & 0 & 1 & 1 & 0 & 2 & 0 & 0 & 4 \\
\hline $\begin{array}{r}\text { Library } \\
\begin{array}{r}\text { Collections, } \\
\text { Acquisitions, E }\end{array}\end{array}$ & 0 & 0 & 1 & 1 & 0 & 0 & 1 & 1 & 1 & 5 \\
Technical Services & & & & & & & & & & \\
\hline $\begin{array}{r}\text { Library Research } \\
\text { E Technical } \\
\text { Services }\end{array}$ & 1 & 2 & 0 & 2 & 0 & 3 & 0 & 2 & 0 & 10 \\
\hline $\begin{array}{r}\text { Reference E User } \\
\text { Services Quarterly }\end{array}$ & 1 & 0 & 0 & 0 & 0 & 1 & 0 & 0 & 3 & 5 \\
\hline Total & 5 & 4 & 7 & 6 & 4 & 7 & 11 & 19 & 5 & 68 \\
\hline
\end{tabular}

Table 2: Number of Articles in Archival Journals Citing Library Journals, 2008-2016

\begin{tabular}{|c|c|c|c|c|c|c|c|c|c|c|}
\hline & 2008 & 2009 & 2010 & 2011 & 2012 & 2013 & 2014 & 2015 & 2016 & Total \\
\hline Archivaria & 0 & 0 & 0 & 0 & 0 & 0 & 1 & 0 & 11 & 2 \\
\hline $\begin{array}{r}\text { Journal of } \\
\text { Archival } \\
\text { Organization }\end{array}$ & 1 & 1 & 1 & 1 & 0 & 2 & 0 & $\mathrm{NA}^{53}$ & NA & 6 \\
\hline $\begin{array}{r}\text { Journal of } \\
\text { the Society of } \\
\text { Archivists } \\
\text { Archives and } \\
\text { Records }{ }^{54}\end{array}$ & 0 & 0 & 0 & 0 & 0 & 0 & 0 & 0 & 0 & 0 \\
\hline $\begin{array}{r}\text { The American } \\
\text { Archivist }\end{array}$ & 0 & 0 & 0 & 1 & 0 & 1 & 3 & 2 & 2 & 9 \\
\hline Archival Issues & 0 & 0 & 0 & 1 & 1 & 0 & 2 & 1 & 0 & 5 \\
\hline Provenance & 0 & 1 & 1 & 0 & 0 & 2 & 0 & 1 & 0 & 5 \\
\hline $\begin{array}{l}\text { RBM: A Journal } \\
\text { of Rare Books, } \\
\text { Manuscripts, and } \\
\text { Cultural Heritage }\end{array}$ & 1 & 1 & 1 & 2 & 2 & 1 & 2 & 3 & 0 & 13 \\
\hline Total & 2 & 3 & 3 & 5 & 3 & 6 & 8 & 7 & 3 & 40 \\
\hline
\end{tabular}


Tables 1 and 2 show that the 770 archival journal articles contain 68 citations of library journals across 40 articles with no steady increase over time, which would be expected if an integration of theory accompanied convergence. Given the relatively small number of results, the citations were further examined to determine if any patterns emerged. An article in The American Archivist in 2015 titled "Archival Divides and Foreign Countries? Historians, Archivists, Information-Seeking, and Technology: Retrospect and Prospect" by Alex H. Poole contains the largest cluster of citations. It cites six articles from College and Research Libraries. ${ }^{55}$ This article does consider the role information technology plays in historians' research, which supports the literature review's assertion that convergence is at least partially driven by patron access to materials.

A subjective grouping of the articles based on their titles shows 7 articles related to digitization and online materials, 1 related to exhibits, and none related to budgeting (although 1 article discusses facilities and likely includes information on budgets). Based on the literature review, convergence would be expected in all these areas. Other large groupings include special collections and libraries (9 articles), classroom and user studies (5 articles), archival literacy and instruction (4 articles), and access and description (4 articles). With the exception of access and description, the literature review does not explicitly identify convergence as happening in these areas although it also does not preclude it. (In the largest grouping, special collections and libraries, however, one might argue convergence is happening as they typically mix books and archival materials.) To aid analysis of the validity of these conclusions and future research, an appendix including the complete list of articles cross-cited is available at the author's institutional repository. ${ }^{56}$

Table 3: Number of Archival Journal Citations Found in Library Journals, 2008-2016

\begin{tabular}{|c|c|c|c|c|c|c|c|c|c|c|}
\hline & 2008 & 2009 & 2010 & 2011 & 2012 & 2013 & 2014 & 2015 & 2016 & Total \\
\hline Archivaria & 0 & 1 & 2 & 0 & 2 & 1 & 0 & 6 & 3 & 15 \\
\hline $\begin{array}{r}\text { Journal of } \\
\text { Archival } \\
\text { Organization }\end{array}$ & 0 & 4 & 1 & 0 & 10 & 0 & 1 & 6 & 0 & 22 \\
\hline $\begin{array}{r}\text { Journal of } \\
\text { the Society of } \\
\text { Archivists } \\
\text { Archives and } \\
\text { Records } \\
5\end{array}$ & 0 & 0 & 0 & 0 & 0 & 0 & 0 & 0 & 0 & 0 \\
\hline $\begin{array}{r}\text { The American } \\
\text { Archivist }\end{array}$ & 2 & 2 & 5 & 4 & 17 & 2 & 3 & 35 & 1 & 71 \\
\hline Archival Issues & 0 & 1 & 1 & 1 & 1 & 0 & 0 & 3 & 1 & 8 \\
\hline Provenance & 0 & 0 & 0 & 1 & 0 & 0 & 0 & 0 & 0 & 1 \\
\hline $\begin{array}{r}\text { RBM: A Journal } \\
\text { of Rare Books, } \\
\text { Manuscripts, and } \\
\text { Cultural Heritage }\end{array}$ & 1 & 0 & 2 & 1 & 7 & 0 & 3 & 3 & 5 & 22 \\
\hline Total & 3 & 8 & 11 & 7 & 37 & 3 & 7 & 53 & 10 & 139 \\
\hline
\end{tabular}


Table 4: Number of Articles in Library Journals Citing Archival Journals, 2008-2016

\begin{tabular}{|c|c|c|c|c|c|c|c|c|c|c|}
\hline & 2008 & 2009 & 2010 & 2011 & 2012 & 2013 & 2014 & 2015 & 2016 & Total \\
\hline $\begin{array}{r}\text { College छळ } \\
\text { Research Libraries }\end{array}$ & 1 & 0 & 1 & 1 & 1 & 2 & 3 & 2 & 2 & 13 \\
\hline $\begin{array}{r}\text { Journal of the } \\
\text { Medical Library } \\
\text { Association }\end{array}$ & 0 & 0 & 0 & 1 & 0 & 0 & 0 & 0 & 0 & 1 \\
\hline $\begin{array}{r}\text { Library } \\
\text { Collections, } \\
\text { Acquisitions, } \mathcal{E}^{\circ} \\
\text { Technical Services }\end{array}$ & 0 & 0 & 1 & 0 & 0 & 0 & 0 & 0 & 0 & 1 \\
\hline $\begin{array}{r}\text { Library Research } \\
\text { \& Technical } \\
\text { Services }\end{array}$ & 0 & 2 & 2 & 2 & 2 & 1 & 2 & 3 & 1 & 15 \\
\hline $\begin{array}{c}\text { Reference E User } \\
\text { Services Quarterly }\end{array}$ & 2 & 0 & 0 & 0 & 0 & 0 & 0 & 1 & 0 & 3 \\
\hline Total & 3 & 2 & 4 & 4 & 3 & 3 & 5 & 6 & 3 & 33 \\
\hline
\end{tabular}

The 1,055 library journal articles contain 139 citations of archival journals across 33 articles (see tables 3 and 4). Again, there is no steady increase over time which would suggest an integration of theory to match the convergence of libraries and archives, although the number of citations spikes in 2012 and 2015. In 2012, the article "Dual Archivist/Librarians: Balancing the Benefits and Challenges of Diverse Responsibilities" by Mary Manning and Judy Silva (discussed in the literature review) cited 28 articles in archival journals. The large number of citations is unsurprising given that the article dealt with dual archivist/librarians. Similarly, the spike in 2015 is not the result of a surge in cross-disciplinary articles, but of a single article ("Reflections on Archival User Studies" by Hea Lim Rhee), which cites articles in archival journals 45 times. ${ }^{58}$ Given the subject matter of the article, this is also not a surprise.

Of the articles in library journals that cite archival journals, five could be considered to be on the topic of digitization or digital materials, and none focus primarily on budgets and exhibits. The most common topic is metadata (seven articles), and three articles deal with special collections. Four articles specifically deal with the topic of archives. These data also do not support the integration of theory as a component of convergence. The number of citations and articles does not increase over time, and articles that include the largest number of cross-citations specifically deal with either archivists or archival user studies, which makes the idea that they represent an integration of archival theory into library scholarship suspect. It is more likely that they are articles dealing with archival subjects that happen to be published in library journals.

\section{Monograph Analysis Methodology}

An OCLC WorldCat search was conducted using the Library of Congress Heading Subject Terms "archives" and "libraries" in the "Subject" field. Limits were set to Year: 2008-2016, Content: Non-Fiction, Format: Book, and Language: English. To limit 
duplicate format results, "Print book" and "Thesis/dissertation" were selected in the results sidebar. For comparison purposes, one search using only the term "archives" and one using only the term "libraries" in the "Subject" field were also conducted, with the same limits.

For further analysis of the topics of the monographs with both subject headings, duplicate results (usually due to differences in the catalog records, for example editions by different publishers, which resulted in some books being listed twice) were removed. Foreign language materials and other nonscholarly works (for example, brief informational brochures cataloged as books, finding aids, and guides to collection holdings) were also removed from the list of works analyzed.

\section{Monograph Analysis Limitations}

While the journal articles in the citations section of this study were peer reviewed and taken from scholarly journals, the monograph analysis may have included nonscholarly materials. Limits were set to "Non-fiction" which (if cataloged correctly) should limit the selection to works that are at least intended to be factual, but may not have undergone peer review or been written as scholarly works. For example, publicity materials about specific libraries and archives were likely included in the sample. Another issue is that the LCSH for special collections is "Libraries $\neq \mathrm{x}$ Special collections." Therefore, works about special collections may discuss matters related to both archives and libraries, but would not necessarily appear in the archives search. Also, subject analysis traditionally requires that a significant portion of a work concern the subject in question to qualify for the inclusion of a subject heading. Some works may have dealt with either archives or libraries, but not in sufficient amounts to qualify for the inclusion of a second LCSH. Finally, the same books seem to have appeared in the search results multiple times based on having the same ISBNs (although different OCLC numbers). This may be either due to differences that required new catalog records (new editions or years of publication that retained the same ISBNs, for example) or through the creation of redundant catalog records.

\section{Monograph Analysis Results}

In total, the search returned 416 results for books with both LCSHs for "Archives" and "Libraries," 10,373 for "Libraries," and 4,500 for "Archives." A breakdown of results by year is shown in table 5 . In terms of raw numbers, works in all three categories have substantially decreased since 2008 . The percentage of books cataloged with both "archives" and "libraries" does not increase as a percentage of the whole for works cataloged with either "archives" or "libraries." This suggests that authors are actually writing fewer books that are being cataloged under both "archives" and "libraries." Similar to the citation analysis, the lack of an increase in either raw numbers or books with "archives" and "libraries" as a percentage of the whole refutes the idea that convergence is occurring in theory being disseminated through such works. 
Table 5: Number of Books and Dissertations Cataloged with "Libraries" and "Archives" LCSHs

\begin{tabular}{|r|r|r|r|r|r|r|r|r|r|}
\hline & $\mathbf{2 0 0 8}$ & $\mathbf{2 0 0 9}$ & $\mathbf{2 0 1 0}$ & $\mathbf{2 0 1 1}$ & $\mathbf{2 0 1 2}$ & $\mathbf{2 0 1 3}$ & $\mathbf{2 0 1 4}$ & $\mathbf{2 0 1 5}$ & $\mathbf{2 0 1 6}$ \\
\hline $\begin{array}{r}\text { Libraries and Archives } \\
\text { LCSH }\end{array}$ & 65 & 67 & 55 & 39 & 39 & 40 & 49 & 38 & 24 \\
\hline Libraries LCSH only & 1488 & 1360 & 1295 & 1105 & 1177 & 1127 & 1125 & 897 & 799 \\
\hline $\begin{array}{r}\text { Libraries and Archives } \\
\text { LCSH/Libraries LCSH }\end{array}$ & $4.4 \%$ & $4.9 \%$ & $4.2 \%$ & $3.5 \%$ & $3.3 \%$ & $3.5 \%$ & $4.4 \%$ & $4.2 \%$ & $3.0 \%$ \\
\hline Archives LCSH only & 611 & 695 & 615 & 508 & 464 & 447 & 464 & 396 & 300 \\
\hline $\begin{array}{r}\text { Libraries and Archives } \\
\text { LCSH/Archives LCSH }\end{array}$ & $10.6 \%$ & $9.6 \%$ & $8.9 \%$ & $7.7 \%$ & $8.4 \%$ & $8.9 \%$ & $10.6 \%$ & $9.6 \%$ & $8.0 \%$ \\
\hline $\begin{array}{r}\text { Libraries or Archives } \\
\text { LCSH }\end{array}$ & 2099 & 2055 & 1910 & 1613 & 1641 & 1574 & 1589 & 1293 & 1099 \\
\hline $\begin{array}{r}\text { Libraries and Archives } \\
\text { LCSH/Libraries or } \\
\text { Archives LCSH }\end{array}$ & $3.1 \%$ & $3.3 \%$ & $2.9 \%$ & $2.4 \%$ & $2.4 \%$ & $2.5 \%$ & $3.1 \%$ & $2.9 \%$ & $2.2 \%$ \\
\hline
\end{tabular}

A further analysis of the works returned with both "archives" and "libraries" as LCSHs was conducted. While additional subject headings were not examined, reading the titles of the results show that 33 of the 237 appear to be about digitization or digital materials; 34 about government records or presidential libraries; 19 about special collections; and 18 about special populations or user communities (LGBTQ+, tribal libraries and museums, latinx users, and aboriginal peoples). Only two titles related to exhibits were found (although lack of "museums" as a LCSH term likely influenced this), and no titles related directly to budgets or budgeting were found; however, two books whose titles suggested they discuss management in general were among the search results.

This provides support for the findings of the literature review that digitization is one area of convergence. Convergence in areas of exhibits and budgeting was not strongly supported, although the present results also do not necessarily refute the literature review due to the exclusion of museums as a LCSH and the relatively narrow scope of budget issues. The number of books concerned with government records and presidential libraries, special collections, and institutions focused on specific communities also suggests that theory is converging (or has converged) in areas where the nature of the institution makes professional identity less of an issue. Presidential libraries, special collections, and community archives and libraries often have archival and library materials intermingled or in close proximity, and work regarding these institutions may reflect a need to draw from both disciplines. However, the possibility remains that books about these institutions draw theory from both disciplines separately with little or no integration and do not represent areas of convergence so much as institutions where the two disciplines exist side-by-side, but are still practiced separately.

\section{Examination of Papers Related to Convergence in LAMs Methodology}

A convenience sample consisting of five white papers and reports was examined for 
if and how theory might be converging in libraries and archives. Members of OCLC recommended two of these papers (Beyond the Silos of the LAMs and Libraries, Archives, and Museums in the Twenty-First Century) and the remainder were selected because they were published recently (Collective Wisdom; Prospects and Strategies for Deep Collaboration; and National Agenda for Continuing Education and Professional Development).

\section{Examination of Papers Related to Convergence in LAMs Limitations}

The largest limitation of this portion of the research is that the selection of papers reviewed was in no way random or scientific and may reflect this author's biases. The selection may also not represent the discussion of convergence as a whole, particularly if the papers' authors were looking at specific areas of convergence that focused on practice and excluded theory.

\section{Examination of Papers Related to Convergence in LAMs Results}

Overall, these documents do not address scholarly publishing or the underlying theory of the various LAM components extensively; however, several papers do recommend greater continuing education and professional development as a means of increasing convergence. The Collective Wisdom paper in particular encourages individuals to engage in scholarship across fields, reinforcing the conclusion that this practice has so far resisted convergence. ${ }^{59}$ The general lack of discussion regarding convergence of theory and advocacy for expanded scholarship across fields also suggests that it is not occurring, or possibly, is not being examined.

In Prospects and Strategies for Deep Collaboration in the Galleries, Libraries, Archives, and Museums Sector, Jill Deupi and Charles Eckman report on the findings of a 2016 summit hosted by the University of Miami where attendees explored opportunities for deeper museum-library collaborations. ${ }^{60}$ The summit focused on increasing collaborative practices, shared budget strategies, joint advocacy and advancement, and future Galleries, Libraries, Archives, and Museums (GLAM) sector summits. ${ }^{61}$ While this paper does address scholarship and interdisciplinary research, it is in the context of collaborative efforts that support faculty and students using resources, not necessarily LIS professionals delving into the theory behind the materials. While it is possible that LIS professionals could use these convergences as examples or case studies, the focus remains on convergence as a means to improve access, which is very much in line with the literature reviews statement that improved access for patrons drives collaboration. The paper in general seems to present convergence as a given for the involved institutions and does not address how the convergence (or lack of convergence) of theory may have been influenced.

Collective Wisdom: An Exploration of Library, Archives and Museum Cultures is the result of a program sponsored by OCLC "which brought together 18 librarians, archivists and museum professionals to form a cohort charged with exploring cross-sector practices and culture with an eye toward increasing interdisciplinary collaborations and 
continuing education." ${ }^{2}$ The cohort quickly discovered "both structural barriers to and multiple opportunities for collaboration, particularly in the arena of professional development and continuing education, but not exclusively so." ${ }^{63}$ These professionals focused on conferences rather than journal publications, but still identified several ways that collaboration might be encouraged, including seeking scholarship outside the field, engaging in cross-sector scholarship, examining opportunities for joint memberships that lead to shared access to journals, and suggesting a wide variety of continuing education and professional development across sectors. ${ }^{64}$ The report does not address the convergence of theory directly, but all of these recommendations can be seen as supporting a greater integration of theory between LAMs either directly (seeking scholarship outside the field) or by broadening professional identities to be more inclusive (continuing education and professional development activities).

The third paper, Beyond the Silos of the $L A M s$, is a report generated by a project with three goals: "to explore the nature of library, archive and museum (LAM) collaborations, to help LAMs collaborate on common services and thus yield greater productivity within their institutions, and to assist them in creating research environments better aligned with user expectations." ${ }^{65}$ This report is very user-focused (particularly in the area of combined digital collections as a means of improving access), but specifically argues that "LAM professionals who understand issues surrounding different types of collections and collecting institutions, and who are not rigidly wedded to their own professional traditions, bring an open-mindedness that allows them to embrace ideas from other professions in the interests of the collaboration." ${ }^{\prime 6}$ The report suggests that this professional flexibility can be encouraged by deliberately learning from professionals in other fields, respecting values and traditions of other fields, and working in close proximity to others. ${ }^{67} \mathrm{As}$ in previous papers, distinct professional identity is seen as a barrier to convergence of LAMs, and the suggested solution is a broadening of professional identity.

The earliest material consulted concerns the Rare Books and Manuscripts Section (RBMS) symposium held in 2006: Libraries, Archives, and Museums in the Twenty-First Century: Intersecting Missions, Converging Futures? ${ }^{68}$ A report describing the reactions of attendees of the conference echoes previous findings, noting the promise of providing access online to collections held by all three types of institutions and differences in professional practices. One attendee reported that during her time in library school "even though the discourse presented among library scholars and professional publications recognized some overlap in the library, archives, and museum fields, they were often nebulous when it came to how these professions could actually work together and be, in a sense, amalgamated into a course of study or an academic program for budding stewards of our cultural heritage." ${ }^{69}$ Although this conference took place 11 years ago, its findings are congruent with more modern reports: professional identity remains an obstacle to convergence.

To one extent or another, these papers speak to the need for continuing education and professional development across LAMs to aid in convergence. This need was seen as 
urgent enough that OCLC issued the National Agenda for Continuing Education and Professional Development across Libraries, Archives and Museums in $2016 .{ }^{70}$ This report focuses on continuing education and professional development, but it is reasonable to assume that workshops would incorporate theory into what they're teaching either explicitly or implicitly. Because some members of the archival profession resist theory, it may also be beneficial to initially focus on practice in continuing education.

Of these papers, three discuss collaboration across institutions rather than convergence: Collective Wisdom, Prospects and Strategies for Deep Collaboration, and Beyond the Silos of the LAMs. This is an important but often unspoken distinction, as collaboration leaves room for professional identities and areas that do not overlap; however, semantically at least, convergence implies LAMs unifying and moving into one institution. Using the term "convergence" when referring to what is actually collaboration creates the impression that continuing education and professional development will result in a merger of professional identities, but the presence of dual archivist/librarians suggests that such efforts may instead result in cross-trained individuals without the merger of theory or professional identity. It is unclear how cross-trained individuals would further convergence between institutions, but it could potentially lead to increased collaboration as more people become familiar with multiple standards, practices, and theory. This also follows the rationale laid out in the context of the literature review: LAMs as institutions converge and cooperate in exhibits, digital collections, and other user access points as well as budgets, while individuals collaborate and still maintain professional identities and practices. And, if theory and scholarly publication are driven by individuals, not institutions, theory can remain separate as long as the individuals understand how different fields' theoretical contexts complement each other well enough to collaborate.

\section{Conclusion}

Overall, the literature review suggests that while libraries and archives may be converging in terms of digitization projects, exhibits, and finance, in other areas, these institutions are not converging. Many professionals with duties associated with librarians and archivists view their jobs as split or dual positions. Archivists in particular do not always appear to engage heavily with theory even in their own profession once out of graduate school, and they prefer to focus on practice. This presents a considerable barrier to integrating archival and library theory. The exact number of archivists who are tenure or nontenure track is not known, but a 2017 study conducted by the Society of American Archivists' Women Archivists Section (WArS) found that of 1,009 respondents, 202 identified as tenure track, and 183 as nontenure track faculty. ${ }^{71}$ While archivists in other classifications certainly engage in scholarly discussions, faculty are more likely to be expected to publish and present as part of their job descriptions and to be allotted critical assistance such as work time, travel funds, and other institutional support to do so. Increasing the number of archivists in faculty positions would result in a greater numbers of archivists engaging in research, and, one would hope, theory, although based on the literature review, such research and subsequent publications might be driven more by practice than by theory. 
The present study also suggests that, in terms of theory, little convergence between libraries and archives is taking place. If so, this implies that convergence may be happening in areas devoid of or at least not heavily influenced by theory; furthermore, if it is accepted that practice grounded in theory is at least partially what separates professionals and nonprofessionals, this convergence may simply represent common areas of deprofessionalization in these fields. Does convergence driven by demand for convenient access have a use for theory, and if not, what does that say about our professional identities in a world that seems to take for granted that convergence is desirable if not a given? Does someone need to understand the concept of original order if patrons are simply going to sort digital images as they desire by the included metadata? Does respect des fonds apply if documents from a dozen OCR'ed collections are going to be searched simultaneously by keyword? The literature review identifies professional identity as a barrier to convergence, which, given the lack of convergence of theory in the present findings, can be interpreted as having some disturbing implications for the future of professional identity in archives and libraries if convergence (as opposed to collaboration) is inevitable.

The present research is not an attempt to sound an alarm against or even deny this convergence categorically, but rather to suggest that if theory remains important to us, perhaps archivists, librarians, and museum curators should consider deliberate discussions regarding the professions' respective theoretical underpinnings and how they interact with each other to make convergence as productive as possible while maintaining (or forging new) professional identities. Archivists may also wish to discuss the importance of theory to the profession and how practitioners can be encouraged to engage more deeply with theory after graduate school. Professional development and continuing education are very sound beginnings for this goal and an excellent way to encourage collaboration, but, at some point, digging deeper will be necessary to see how theory interacts among and complements these fields. An obvious initial step here would be more active attempts to read and publish in journals in the other areas (for archivists particularly, as the literature review suggests). Such discussions may also be a way to identify areas where collaboration may be possible, which, given the linked data environment on the horizon, may further benefit our institutions and our patrons. Evidence shows that the occurrence of citations between archival and library journals is rare between 2008 and 2016. Increasing these numbers would benefit both professions, although generating these kinds of discussions may represent a significant barrier to successful integration of libraries and archives. Overall, while effort to engage more broadly with theory and scholarly literature from professionals in other types of institutions may never result in a Grand Unified Theory of LAMs, it can lend additional perspectives to areas of convergence and increase collaboration, leading to a more nuanced, subtle view of how libraries, archives, and museums can better serve patrons. 


\section{ABOUT THE AUTHOR}

Eric Willey is the special collections and formats cataloger at Illinois State University. He has previously worked as an intern at the Illinois Regional Archives Depository at Western Illinois University, as a project assistant with the McCormick-International Harvester Collection at the Wisconsin Historical Society, and as an associate curator at the Filson Historical Society in Louisville, Kentucky. For other publications by Willey, see orcid.org/0000-0002-7514-0011.

\section{NOTES}

1. Valuable advice and critiques of this article were provided by Eric Childress, Cory Nimer, Christine Oliver, Pat Riva, Chad Kahl, Susan Franzen, and Alexandra Orchard. Errors remain the sole responsibility of the author.

2. Roughly synonymous acronyms to refer to groups of cultural heritage institutions include GLAMs (Galleries, Libraries, Archives, and Museums) and LAMMS (Libraries, Archives, Museums, Monuments, and Sites).

3. "About," SNAC, http://snaccooperative.org/static/about/about.html; "Data Contributors," SNAC, http://snaccooperative.org/static/about/datacontrib.html.

4. Chris Oliver et al., "Working Group on FRBR/CRM Dialogue," IFLA, June 8, 2014, https:// www.ifla.org/node/928.

5. Jeanette A. Bastian, Megan Sniffin-Marinoff, and Donna Weber, Archives in Libraries: What Librarians and Archivists Need to Know to Work Together (Chicago: Society of American Archivists, 2015), 117.

6. Ibid., 117-18.

7. Wendy Duff et al., "From Coexistence to Convergence: Studying Partnerships and Collaboration among Libraries, Archives, and Museums," Information Research 18, no. 3, paper 585, http:// InformationR.net/ir/18-3/paper585.html.

8. Ibid.

9. Ibid.

10. Jackie Dooley, The Archival Advantage: Integrating Archival Expertise into Management of Born-digital Library Materials (Dublin, Ohio: OCLC Research, 2015), 5, http://www.oclc.org/content/dam/ research/publications/2015/oclcresearch-archival-advantage-2015.pdf.

11. Ibid., 24.

12. Deanna Marcum, "Archives, Libraries, Museums: Coming Back Together?," Information छ Culture 49, no. 1 (2014): 75.

13. Ibid., 79 .

14. Ibid., 80 .

15. Kara Van Malssen, "BIBFRAME AV Modeling Study, Defining a Flexible Model for Description of Audiovisual Resources" (2014), 2, http://www.loc.gov/bibframe/docs/pdf/bibframe-avmodelingstudy-may15-2014.pdf.

16. Ibid., 2.

17. Ibid., 10 .

18. Fidelia Ibekwe-SanJuan and Elaine Ménard, "Preface: Archives, Libraries, and Museums in the Era of the Participatory Social Web," Canadian Journal of Library and Information Science 39, nos. 3-4 (2015): 245.

19. Ibid., 246 . 
20. Ibid., 250 .

21. Cheryl Klimaszewski, "Lumping (and Splitting) LAMs: The Story of Grouping Libraries, Archives, and Museums," Canadian Journal of Library and Information Science 39, nos. 3-4 (2015): 351.

22. Ibid., 352 .

23. Ibid., 353 .

24. Ibid., 355 .

25. Ibid., 357.

26. "GPAS Curriculum," Society of American Archivists, https://www2.archivists.org/prof-education/ graduate/gpas/curriculum.

27. 2018 ACA Exam Application, Academy of Certified Archivists, https://certifiedarchivists.wufoo .com/forms/q11qi7kn1y8nbb7.

28. Ann Wheeler, "A Cataloger and an Archivist: Katherine Ryner and St. Mary's College of Maryland," College \& Research Library News 69, no. 7 (2008): 390.

29. Mary Manning and Judy Silva, "Dual Archivist/Librarians: Balancing the Benefits and Challenges of Diverse Responsibilities," College E Research Libraries (March 2012): 165-66.

30. Ibid., 166 .

31. Ibid., 174.

32. Cory L. Nimer, "Reading and Publishing within the Archives Community: A Survey," The American Archivist 72 (Fall/Winter 2009): 318.

33. Ibid., 319.

34. Ibid., 321-22.

35. Ibid., 323 .

36. Ibid., 325 .

37. John Roberts, "What Is Archival Theory and Why Is It Important? Responses to Terry Eastwood's Paper," Archivaria 37 (Spring 1994): 131.

38. Kathleen Fear and Paul Conway, "Valuing the American Archivist: An Interpretation of SAA's First Readership Survey," The American Archivist 74, no. 2 (2011): 693-94.

39. Ibid., 695.

40. Laura Manzari, "Library and Information Science Journal Prestige as Assessed by Library and Information Science Faculty," Library Quarterly: Information, Community, Policy 83, no. 1 (2013): 42.

41. Ibid., 46-47.

42. Stephanie Allen et al., Collective Wisdom: An Exploration of Library, Archives and Museum Cultures (Dublin, Ohio: OCLC Research, 2017), http://www.oclc.org/content/dam/research/publications/2017/collective-wisdom-white-paper.pdf.

43. Ibid., 7 .

44. Council Meeting Minutes, Society of American Archivists, May 16-17, 2017, SAA Headquarters, Chicago, Illinois, 17, https://www2.archivists.org/sites/all/files/0517\%20Council\%20Minutes_ AsAdopted060817_0.pdf

45. Future of ALA/SAA/AAM Joint Committee on Archives, Libraries and Museums (CALM), Council Meeting Minutes, Society of American Archivists, May 16-17, 2017, Chicago, Illinois, 1, https://www2.archivists.org/sites/all/files/0517-V-A-CALM.pdf.

46. Council Meeting Minutes, 17.

47. Jungfeng Xia, "Positioning Open Access Journals in a LIS Journal Ranking," College E Research Libraries (March 2012): 135.

48. Ibid., 139.

49. Judith M. Nixon, "Core Journals in Library and Information Science: Developing a Methodology for Ranking LIS Journals," College \& Research Libraries (January 2014): 66.

50. Ibid., 84 .

51. Ibid., 84 . 
52. They are The American Archivist, Archival Issues, Archivaria, Journal of Archival Organization, and Provenance. Nimer, "Reading and Publishing," 319.

53. At the time of writing, Journal of Archival Organization had not published any issues after volume 12, 2014. See Journal of Archival Organization, Taylor \& Francis Online, http://www.tandfonline .com/loi/wjao20

54. Published as the Journal of the Society of Archivists (1955-2012) and Archives and Records: The Journal of the Archives and Records Association (2013-).

55. Alex H. Poole, "Archival Divides and Foreign Countries? Historians, Archivists, InformationSeeking, and Technology: Retrospect and Prospect," The American Archivist 78, no. 2 (2015): 375-433.

56. Eric Willey, "An Examination of the Convergence of Theory in Libraries and Archives, Additional Files, Appendix.docx," ISU ReD: Research and eData (December 2017), https://ir.library.illinoisstate .edu/fpml/85/.

57. Citations for both the current and previous title were searched for in articles published from 2013 to 2016 .

58. Hea Lim Rhee, "Reflections on Archival User Studies," Reference E' User Services Quarterly 54, no. 4 (2015): 29-42.

59. Allen et al., A6.

60. Jill Deupi and Charles Eckman, "Prospects and Strategies for Deep Collaboration in the Galleries, Libraries, Archives, and Museums Sector" (Academic Art Museum and Library Summit, Coral Gables, Florida, January 2016), 1, http://scholarlyrepository.miami.edu/con_events_aamls2016/1.

61. Ibid., 2.

62. Allen et al., 6 .

63. Ibid.

64. Ibid.

65. Diane M. Zorich, Günter Waibel, and Ricky Erway, Beyond the Silos of the LAMs: Collaboration among Libraries, Archives, and Museums (OCLC Research Publication, 2008), 8, www.oclc.org/ research/publications/library/2008/2008-05.pdf.

66. Ibid., 27.

67. Ibid., 28.

68. Christian Dupont. "Libraries, Archives, and Museums in the Twenty-First Century: Intersecting Missions, Converging Futures?," RBM: A Journal of Rare Books, Manuscripts, and Cultural Heritage 8, no. 1 (2007): 13-19, http://rbm.acrl.org/index.php/rbm/article/view/271/271.

69. Ibid., 16-18.

70. Christina Drummond et al., eds., National Agenda for Continuing Education and Professional Development across Libraries, Archives and Museums (Dublin, Ohio: OCLC Research, 2016), http://www .oclc.org/content/dam/research/publications/2016/oclcresearch-national-agenda-lams-educationdevelopment-2016.pdf.

71. Stacie Williams, e-mail to author re: 2017 WArS/SAA Salary Survey question, 2017. These numbers are from the original raw data, and some responses may have been taken out during data cleaning (the survey did not specifically break down respondents by job classification, and this information was provided as a much-appreciated courtesy to the author). 